\title{
Pendampingan UKM Tahu Kampung Trunan Magelang Melalui Strategi Pemasaran POSM dan WOM
}

\author{
Tofu Sme Empowerment in Trunan Magelang Through POSM and WOM as \\ Marketing Strategy
}

\author{
${ }^{1)}$ Andhatu Achsa, ${ }^{2}$ Dian Marlina Verawati, ${ }^{3 *}$ Ivo Novitaningtyas \\ ${ }^{1,2,3)}$ Program Studi Manajemen, Fakultas Ekonomi \\ Universitas Tidar \\ J1. Kapten Suparman 39 Magelang \\ *email: ivo.novitaningtyas@untidar.ac.id
}

DOI:

\section{ABSTRAK}

10.30595/jppm.v5i1.8580

Program pengabdian ini dilatarbelakangi oleh permasalahan mitra yaitu menurunnya volume penjualan. Tujuan dari program ini adalah meningkatkan

Histori Artikel: pemahaman dan kemampuan mitra terhadap strategi pemasaran POSM dan WOM. Program dilaksanakan menggunakan metode sosialisasi dan pelatihan

Diajukan:

$16 / 09 / 2020$ kepada 20 UKM tahu sebagai sasaran program. Hasil pelaksanaan program menunjukkan bahwa terdapat peningkatan pemahaman mitra terhadap strategi POSM dan WOM dalam rangka meningkatkan minat beli konsumen, serta

Diterima:

$10 / 01 / 2022$ peningkatan keterampilan mitra dalam membuat material pendukung POSM untuk menarik minat beli konsumen. Melalui pelaksanaan program ini diharapkan agar minat beli konsumen terhadap produk UKM tahu meningkat sehingga berdampak

Diterbitkan:

$16 / 02 / 2022$ pada peningkatan volume penjualan dan menjadi solusi bagi permasalahan mitra.

Kata kunci: Pemasaran; POSM; UKM; WOM

\section{ABSTRACT}

This program aims to increase the partner's understanding and capabilities about POSM and WOM as a marketing strategy in order to increase sales volume. The program is implemented using socialization and training methods to 20 tofu SMEs as the target of this program. The results of the program implementation show an increase in participant's understanding of the POSM and WOM strategy in order to increase consumer buying intention. Moreover, it is also increasing the skills to make supporting material for POSM to attract the consumer. Through the implementation of this program, it is hoped that consumer buying intention in tofu SME products will increase, so it will have an impact on increasing sales volume and become a solution to their problems.

Keywords: Marketing; POSM; SME; WOM

\section{PENDAHULUAN}

UKM berperan penting dalam perekonomian Indonesia. Kontribusi UKM diantaranya adalah menjadi penggerak perekonomian, mendukung pertumbuhan ekonomi nasional dan menciptakan lapangan kerja sehingga dapat mengurangi pengangguran (Werdani, et al., 2020).
Walaupun demikian, sebagian besar UKM memiliki permasalahan yang hampir sama. Permasalahan tersebut berkaitan dengan keterbatasan permodalan, kualitas sumber daya manusia, dan strategi untuk memasarkan produk (Maulida \& Yunani, 2018). Oleh sebab itu diperlukan pendampingan pada UKM agar 
mampu menemukan solusi sebagai penyelesaian masalah yang dihadapi.

Kampung Trunan merupakan salah satu sentra UKM yang memproduksi tahu di Kota Magelang. Adapun para produsen tahun di Kampung Trunan menjadi anggota dari Primer Koperasi Produsen Tempe Tahu Indonesia (PRIMKOPTI). Koperasi tersebut menjadi sarana untuk menghimpun, memberdayakan potensi, serta membina produsen tahu di Kampung Trunan. Walaupun demikian, jumlah anggotanya mengalami penurunan sehingga proses simpan-pinjam di PRIMKOPTI juga menurun. Permasalahan lainnya yang dihadapi oleh UKM tahu di Kampung Trunan adalah menurunnya volume penjualan.

Pemasaran menjadi salah satu unsur yang penting dalam pengembangan bisnis UKM (Bukit, et al., 2019; Yunita \& Purwanto, 2020). Pemasaran mencakup strategi pengembangan produk, penetapan harga, distribusi produk dan promosi produk (Kotler $\&$ Keller, 2018). Strategi pemasaran yang tepat dapat mendukung daya saing produk UKM melalui peningkatan minat beli konsumen (Garside et al., 2020). Selain itu, pemasaran yang berorientasi pada pelanggan juga berfungsi menciptakan pasar yang loyal. Dengan memiliki pelanggan yang loyal maka diharapkan bisnis UKM dapat terus berkelanjutan.

Pemasaran dijelaskan sebagai serangkaian aktivitas untuk menciptakan, mengkomunikasikan dan menyampaikan produk yang bernilai bagi konsumen (Tjiptono \& Chandra, 2017). Oleh sebab itu, strategi komunikasi pemasaran merupakan faktor penting yang menentukan keberhasilan pemasaran suatu produk kepada konsumen (Hambali et al., 2018). Adapun UKM tahu Kampung Trunan memiliki produk tahu basah dan keripik tahu. Walaupun demikian, mereka belum menerapkan komunikasi pemasaran yang meningkatkan minat beli konsumen pada titik penjualannya atau Point of Sale (POS). Selain itu, mereka kurang memahami pentingnya menerapkan pemasaran yang berorientasi pada kepuasan dan loyalitas pelanggan.
Tinjauan terhadap penelitian terdahulu membuktikan bahwa penerapan Point of Sale Merchandising (POSM) mempengaruhi minat beli konsumen sehingga berdampak pada peningkatan volume penjualan (Katrin \& Vanel, 2020). Selain itu, jika pemasar mampu menciptakan daya tarik melalui POSM sehingga konsumen puas terhadap produk, maka konsumen yang puas berpotensi menjadi pelanggan yang loyal (Schiffman \& Kanuk, 2008). Pelanggan yang loyal atau konsumen yang memiliki tingkat kepuasan yang tinggi akan bersedia menceritakan hal-hal positif tentang produk dan merekomendasikan produk kepada calon konsumen lainnya yang dikenal dengan WOM (Swara \& Putri, 2018). Lebih lanjut, promosi dari mulut ke mulut atau Word of Mouth (WOM) berdampak pada peningkatan minat beli dan keputusan pembelian (Juniantoko \& Supriono, 2017).

Berdasarkan permasalahan pada aspek komunikasi pemasaran, maka diperlukan pendampingan bagi UKM tahu di Kampung Trunan melalui pengabdian kepada masyarakat yang adalah salah satu bentuk tridharma perguruan tinggi. Oleh sebab itu, tujuan dari program pengabdian kepada masyarakat pada UKM tahu di Kampung Trunan adalah meningkatkan pemahaman terhadap strategi POSM dan WOM melalui sosialisasi, pelatihan dan pendampingan. Dengan demikian, diharapkan agar minat beli konsumen terhadap produk UKM tahu meningkat. Sehingga volume penjualan produk meningkat dan berdampak pada peningkatan kesejahteraan UKM tahu.

\section{METODE}

Untuk mencapai tujuan program pengabdian kepada masyarakat, maka metode yang digunakan pada UKM tahu di Kampung Trunan adalah sosialisasi dan pelatihan. Adapun peserta atau mitra adalah 20 orang anggota PRIMKOPTI yang merupakan UKM tahu. Sosialisasi dilaksanakan untuk meningkatkan pengetahuan, pemahaman dan kesadaran peserta terhadap pentingnya strategi POSM dan WOM untuk meningkatkan minat beli konsumen. Lebih lanjut, pelatihan dilaksanakan dengan kegiatan tutorial bagaimana membuat material pendukung pada 
POSM agar meningkatkan keterampilan peserta.

Berikut ini adalah uraian dari metode pelaksanaan kegiatan:

1. Sosialiasi strategi POSM.

2. Pelatihan pembuatan material pendukung POSM.

3. Sosialisasi strategi WOM.

4. Sosialisasi peningkatan minat beli dan volume penjualan

\section{HASIL DAN PEMBAHASAN}

Kegiatan sosialisasi dan pelatihan diselenggarakan di gedung PRIMKOPTI yang terletak di Jalan Beringin VI No. 1 Kelurahan Tidar Selatan,Kecamatan Magelang Selatan, Kota Magelang. Kegiatan pengabdian dilakukan dalam 3 tahap yaitu (1) pra kegiatan berupa diskusi isu-isu dan fenomena yang berkembang di UKM terkait pemasaran, (2) penyampaian materi pertama tentang strategi POSM, penyampaian materi kedua tentang pelatihan pembuatan material pendukung, penyampaian materi ketiga tentang strategi WOM, dan penyampaian materi keempat yaitu peningkatan minat beli dan volume penjualan, serta (3) tahap pasca kegiatan yaitu evaluasi melalui pertanyaan interaktif maupun tanggapan terhadap materi, dan simpulan materi.

Tahap pertama yaitu pra kegiatan dilaksanakan untuk mengetahui tingkat kesadaran peserta terhadap pentingnya strategi pemasaran dalam rangka meningkatkan minat beli konsumen. Selain itu, pada tahap ini juga dilakukan diskusi dengan peserta terkait isuisu yang berkaitan dengan POSM dan WOM. Hasil kegiatan tahap pertama menunjukkan bahwa peserta belum memahami pentingnya menerapkan POSM untuk meningkatkan minat beli konsumen. Selain itu, peserta juga menyatakan belum pernah membuat material pendukung seperti poster dan stiker, sedangkan sebagian kecil peserta telah memiliki material pendukung berupa spanduk. Sebagian peserta juga belum menyadari pentingnya WOM sebagai sarana promosi pemasaran.

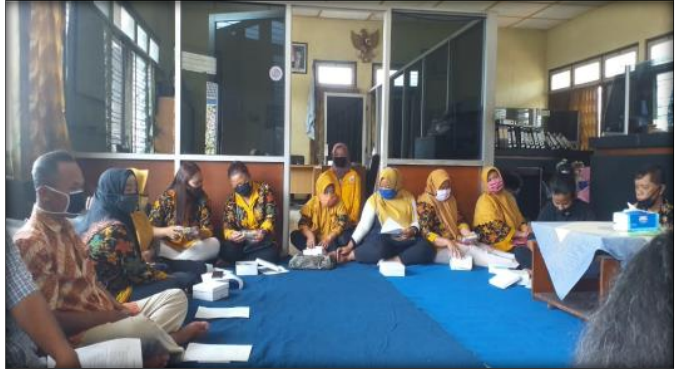

Gambar 1. Peserta Kegiatan

Tahap kedua yaitu pelaksanaan kegiatan terdiri dari 4 materi yang disampaikan kepada peserta. Materi pertama yaitu implementasi strategi POSM. Pada materi yang pertama, diberikan pemahaman kepada peserta mengenai apa itu Point of Sale (POS) serta dimana titik POS untuk masingmasing peserta UKM tahu. Selain itu, fungsi dari POS, pentingnya menampilkan display yang menarik minat konsumen dan contoh material pelengkap POS juga disampaikan kepada peserta pada materi yang pertama. Setelah dilakukan penyampaian materi pertama, selanjutnya diberikan pelatihan pembuatan material pendukung POSM kepada peserta. Peserta dijelaskan tentang contoh material pendukung POSM seperti poster, sticker, dan spanduk, serta tutorial bagaimana membuat desain yang menarik. Materi dan pelatihan yang diberikan kepada peserta bertujuan untuk meningkatkan pemahaman, pengetahuan, kesadaran dan keterampilan peserta terhadap strategi POSM untuk meningkatkan minat beli konsumen. Metode pelatihan dan pendampingan dibuktikan menjadi salah satu metode yang efektif dan berdampak pada peningkatan pemahaman dan keterampilan peserta (Bahrudin et al., 2020; Werdani et al., 2020).

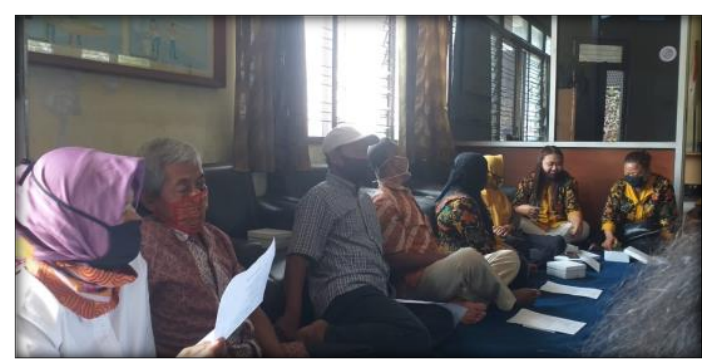

Gambar 3. Pelaksanaan Tutorial Pelatihan Membuat Material Pendukung POSM 
Adapun materi ketiga berisi tentang strategi WOM. Pada materi ketiga dijelaskan 3 elemen kunci dalam pemasaran yaitu produk yang berkualitas, konsumen yang puas, dan pelanggan yang loyal. Hal tersebut sesuai dengan teori yang dikemukakan oleh peneliti terdahulu dan pakar pemasaran (Purbandari et al., 2018; Tjiptono \& Chandra, 2017). Pada materi ketiga juga dijelaskan 5T elemen WOM yaitu pembicara (talkers), topik (topics), alat komunikasi (tools), partisipasi (talking part), dan pengawasan (tracking), serta disampaikan juga bagaimana strategi menghasilkan produk yang berkualitas agar memuaskan pelanggan sehingga pelanggan dapat menerapkan WOM.

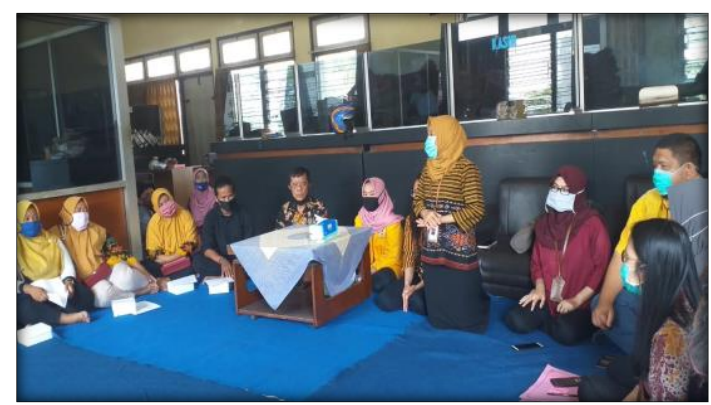

Gambar 3. Pelaksanaan Sosialisasi

Lebih lanjut, materi terakhir yang diberikan kepada peserta adalah pentingnya komunikasi pemasaran serta bagaimana cara untuk meningkatkan minat beli konsumen dan omset penjualan. Pada materi tersebut juga diberikan motivasi bagi peserta untuk menumbuhkan kesadaran terhadap pentingnya penerapan strategi komunikasi pemasaran yang sesuai.

Pada tahap pasca kegiatan dilaksanakan evaluasi melalui diskusi dan pertanyaan interaktif. Hasil evaluasi menunjukkan bahwa sebagian besar peserta mulai memahami dan mengetahui materimateri yang sudah disampaikan dalam sosialiasi dan pelatihan. Selain itu peserta pelatihan juga aktif dalam memberikan pertanyaan terhadap materi yang kurang jelas, dan antusias mengikuti kegiatan. Lebih lanjut hasil evaluasi kegiatan sosialisasi dan pelatihan juga menunjukkan peningkatan pemahaman peserta/mitra terkait strategi POSM dan WOM yang direpresentasikan melalui grafik pada gambar 4 .

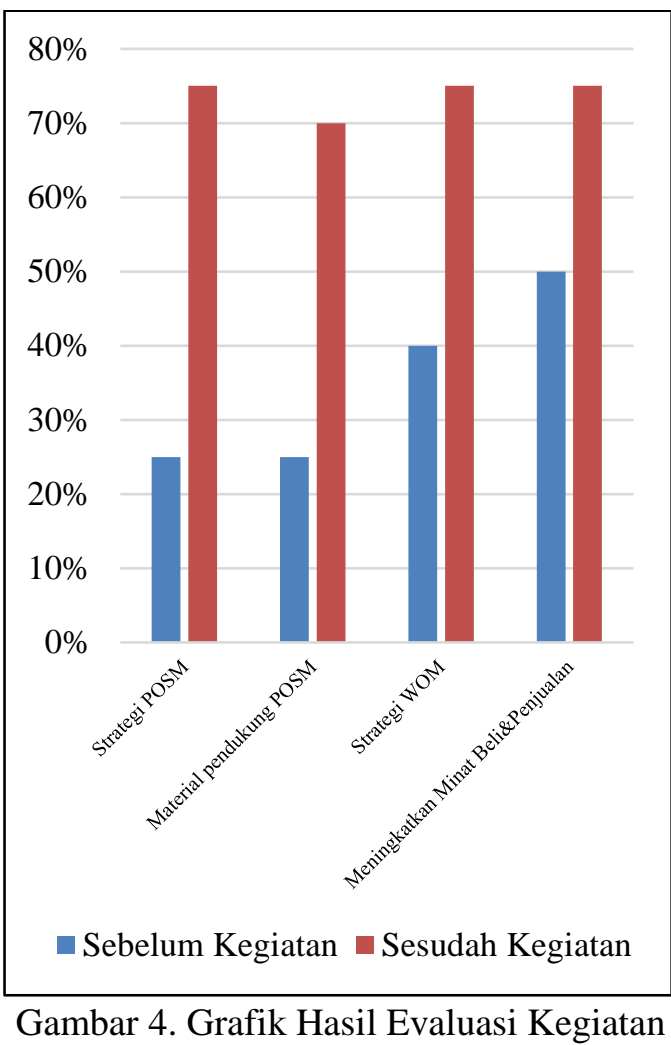

Berdasarkan hasil tersebut, maka terdapat peningkatan pengetahuan peserta/mitra tentang strategi POSM, strategi WOM, dan strategi meningkatkan minat beli serta volume penjualan. Selain itu, kemampuan peserta/mita dalam membuat desain material pendukung POSM juga mengalami peningkatan. Dengan demikian diharapkan agar peserta/mitra mampu membuat material pendukung dengan desain yang menarik untuk menerapkan strategi POSM sehingga menarik minat beli konsumen. Setelah konsumen membeli, maka diperlukan pelayanan yang memuaskan selama transaksi jual beli di POS dan produk yang berkualitas, sehingga konsumen akan puas. Jika konsumen puas maka konsumen akan melakukan pembelian berulang sehingga berpotensi menjadi pelanggan yang loyal. Pelanggan yang loyal akan mempromosikan produk melalui WOM. Pelaksanaan WOM diharapkan dapat meningkatkan volume penjualan produk dari UKM tahu di Kampung Trunan. 


\section{SIMPULAN}

Sosialisasi tentang strategi pemasaran POSM dan WOM yang dilaksanakan di UKM tahu Kampung Trunan anggota PRIMKOPTI mampu memberikan pemahaman dan pengetahuan bagi mitra dalam menerapkan strategi untuk meningkatkan minat beli konsumen dan volume penjualan produk. Pelatihan pembuatan desain material pendukung POSM berupa poster, sticker dan spanduk dapat meningkatkan kemampuan mitra untuk menata display dari point of sale sehingga diharapkan meningkatkan daya tarik produk pada persepsi konsumen. Dengan demikian, diharapkan minat beli konsumen meningkat, serta konsumen yang puas menjadi loyal. Pelaksanaan pendampingan melalui sosialisasi dan pelatihan dapat menjadi solusi untuk mengatasi permasalahan mitra.

\section{UCAPAN TERIMA KASIH}

Ucapan terima kasih kepada Universitas Tidar, Bapak Sumardi DS (Kepala PRIMKOPTI), dan seluruh UKM tahu di Kampung Trunan yang telah mendukung dalam pelaksanaan program Pengabdian Kepada Masyarakat ini.

\section{DAFTAR PUSTAKA}

Bahrudin, A., Widdiyanti, \& Wahyono. (2020). Pemberdayaan Masyarakat Melalui Pengembangan Desain Produk ANyaman Mansiang di Jorong Taratak Nagari Kubang Kecamatan Guguak, Kabupaten Limapuluh Kita. JPPM (Jurnal Pengabdian Dan Pemberdayaan Masyarakat), 4(1).

Bukit, F. R. A., A.S, G. G., Irvan, I., \& Fahmi, F. (2019). Pembuatan Website Katalog Produk UMKM Untuk Pengembangan Pemasaran dan Promosi Produk Kuliner. JPPM (Jurnal Pengabdian Dan Pemberdayaan Masyarakat), 3(2), 229. https://doi.org/10.30595/jppm.v3i2.4317

Garside, A. K., Baroto, T., \& Gunarimba Waibo, O. R. (2020). Penguatan Aspek Produksi dan Pemasaran pada Usaha Keripik Singkong Mix Sayur. JPPM (Jurnal Pengabdian Dan Pemberdayaan
Masyarakat),

$4(1)$ 61. https://doi.org/10.30595/jppm.v0i0.4614

Hambali, Astrid, G., \& Utari, Y. (2018). Strategi Komunikasi Pemasaran Dalam Meningkatkan Jumlah Penginap di Hotel Best Skip Palembang. Jurnal Studi Sosial Dan Politik, 2(1), 44-55.

Juniantoko, A. D., \& Supriono. (2017). Pengaruh Word of Mouth terhadap Minat Beli serta dampaknya pada Keputusan Pembelian. Jurnal Administrasi Bisnis (JAB), 53(2), 11-18.

Katrin, K., \& Vanel, Z. (2020). Strategi Pemasaran Komunikasi Digital Marketing Platform (Cashbac) Untuk Meningkatkan Daya Beli Konsumen. SOURCE: Jurnal Ilmu Komunikasi, 6(1), 14. https://doi.org/10.35308/source.v6i1.175 3

Kotler, P., \& Keller, K. L. (2018). Manajemen Pemasaran Edisi Kedua Belas Jilid 2. Indeks.

Maulida, S., \& Yunani, A. (2018). Peluang dan Tantangan Pengembangan Usaha Mikro Kecil Menengah (UMKM) Dari Berbagai Aspek Ekonomi. Jurnal Ilmiah Manajemen \& Bisnis, 2(1).

Purbandari, E., Sugandini, D., \& Sutiono, H. T. (2018). Word of Mouth Sebagai Konsekuensi Kepuasan Pelanggan. Jurnal Manajemen Dan Pemasaran Jasa, $11(1)$, 111. https://doi.org/10.25105/jmpj.v11i1.2355

Schiffman, L., \& Kanuk, L. L. (2008). Perilaku Konsumen. PT Indeks.

Swara, N. N. A. A. V., \& Putri, N. M. K. D. (2018). Peran Word Of Mouth Memediasi Pengaruh Kepuasan Terhadap Loyalitas Konsumen Pada Green Product Merek Oriflame Di Kota Denpasar. Jurnal Widya Manajemen, 1(1), 80-98. https://doi.org/10.2307/j.ctt6wrb1x.39

Tjiptono, F., \& Chandra, G. (2017). Pemasaran Strategik Edisi 3. Penerbit Andi.

Werdani, R. E., Kurniawati, N. I., Sukoco, J. 
Andhatu Achsa, Dian Marlina Verawati, Ivo Novitaningtyas

B., Windriya, A., \& Iskandar, D. (2020). Pelatihan Pemasaran Produk Homemade Melalui Sosial Media. JPPM (Jurnal Pengabdian Dan Pemberdayaan Masyarakat), 4(1), $\quad 1$. https://doi.org/10.30595/jppm.v4i1.4655

Yunita, A., \& Purwanto, H. (2020). Peningkatan Pemasaran Produk Kerajinan Bambu di Dusun Sanggrahan I, Desa Muntuk, Dlingo, Bantul. JPPM (Jurnal Pengabdian Dan Pemberdayaan Masyarakat), $4(1)$. https://doi.org/10.30595/jppm.v0i0.4603 